\title{
The Analysis of Relationship between Fourth Grade College Students' Attendance Rate and Their Postgraduate Rate and Employment Rate
}

\author{
Teng Hui \\ School of International Trade and Economics \\ Shandong University of Finance and Economics \\ Jinan, Shandong Province, China
}

\begin{abstract}
In recent years, the employment pressure of university graduates has become more and more great, which has led a decline in the attendance rate of Grade 4 students. Consequently, many universities took a lot of measures for the Grade 4 students to apply for employment as well as prepare the postgraduate exam. From a quantitative point of view, this paper studies the relationship between the attendance rate of Grade 4 students and their postgraduate entrance rate as well as the employment rate through correlation analysis and Granger causality analysis. It finds that there is no significant correlation between attendance rate and the postgraduate rate and the employment rate, while there is a negative linear correlation between the postgraduate rate and the employment rate.
\end{abstract}

Keywords-Attendance Rate; Correlation Analysis; Granger Causality Analysis

\section{INTRODUCTION}

In recent years, under the increasingly severe employment situation, the phenomenon of skipping classes of university Grade 4 students becomes very common. According to some investigations, the average attendance rate has been less than $50 \%$. Under the guise of preparing the postgraduate exam, internships, looking for jobs and so on, the students are absentminded for their absence of classes. As for the university administration, under the pressure of graduates' employment, they have no choice but to lower the Grade 4 students' attendance rate requirement and give the students convenience for the above excuses. This situation is a common problem in Chinese universities. On one hand it affects the quality of talent training in universities, on the other hand it also causes a great waste of educational resources. As the students are not in school, the teaching can not be carried out normally. And the student administration work is also difficult to carry out due to many notices can not be timely informed. As a result, the teachers can not understand the situation of students in time, which increases the difficulty of management. This increasingly common phenomenon of "shrinkage of Grade 4 studies" has seriously affected the normal teaching and administration of universities.

Because of many reasons, it becomes a common

This article is sponsored by National Statistical Science Research Project: Research on forth college students' education management based on statistical analysis technology, project number: 2010LC71. problem regarding the low attendance rate of Grade 4 students, disorder in administration, and obvious declining of graduation thesis in Chinese universities at present. And this phenomenon as "shrinkage of Grade 4 studies" has caused the attention of many universities and teachers. Various employees of universities analyzed the deep causes of the phenomenon of "empty nest" in senior 4 combining with their own work practice and from the different angles of teaching management, education management and teaching reform, and puts forward some feasible suggestions. For example, the documents [1-14] quoted by this paper mainly studied and probed into the management of the phenomenon of deficiency in grade 4 of universities from the qualitative point of view. The documents [15-17] quoted by this paper studied the relationship between the attendance rate and the construction of the study ethos, the exam scores and the related education management utilizing the statistical analysis tools. In general, the research on the teaching and education of the Grade 4 mostly studied from the qualitative point of view, and there are few support for data analysis.

Based on the actual investigation data and using the statistical quantitative analysis tool, this paper studies the relationship between the Grade 4 students' attendance rate and the postgraduate rate and also the employment rate. The results of this study can provide policy advice and guidance for the education and teaching management of the Grade 4 students in universities. 


\section{StATISTICAL MethodS}

\section{A. Correlation Analysis}

Correlation analysis is a statistical analysis method to investigate the linear relationship between two variables. To investigate the linear relationship between two variables, we must analyze them considering two important factors, one is the intensity of correlation, the other is the direction of correlation. Pearson correlation coefficient is used to study the degree and direction of linear correlation between two variables. The formula is as follows:

$$
r=\frac{\sum\left(x_{i}-\bar{x}\right)\left(y_{i}-\bar{y}\right)}{\sqrt{\sum\left(x_{i}-\bar{x}\right)^{2} \sum\left(y_{i}-\bar{y}\right)^{2}}}
$$

Among them, the Pearson correlation coefficient is represented by $r$, the two variables are represented by $x_{i}$ and $y_{i}$, and the mean value of the two variables is represented by $\bar{x}$ and $\bar{y}$.

Pearson correlation coefficient has the following properties:

(1) the span of this coefficient is $-1 \leq r \leq+1$;

(2) When $r$ is positive, there is a positive correlation between the two variables.

(3) When $r$ is negative, there is a negative correlation between the two variables.

(4) The greater the absolute value of the correlation coefficient $|\mathrm{r}|$ is, the closer the correlation degree between the two variables is. When $r=+1$, it is a completely positive correlation. When $\mathrm{r}=-1$, it is a completely negative correlation, when $r=0$, the two variables are completely independent.

\section{B. Granger Causality Analysis}

We assume other conditions are invariant. If there is a significant change in the prediction accuracy to $y_{i}$ after adding the lag variable $x_{i}$, we deem $x_{i-1}$ has the Granger causality to $y_{i}$. For convenience, the $x_{i-1}$ 's Granger causality to $y_{i}$ is usually expressed as $x_{i}$ 's causality relationship to $y_{i}$.

The essence of the causality test proposed by Granger (1969) and Sims (1972) is to determine whether one variable can help predict another variable. If the variable $x$ is helpful to predict the variable $y$, that is, when we carry out autoregressive analysis on $y$ according to the past value of $y$, if we add the past value of $x$, it can significantly enhance the interpretation ability of regression, and then $x$ is called the Granger cause of $y$, otherwise, $x$ is non-Granger cause of $y$.

The correlation coefficient can only reflect the degree of correlation between variables, but it can not reflect the causality between them. So we use the Granger causality analysis method in econometrics to analyze the attendance rate and the postgraduate rate. To get the causality result between them is helpful for further statistical analysis.

\section{EMPIRICAL STUDY}

The data are from 220 Grade 4 students and their teachers' teaching records within a college. Data processing and statistical analysis are mainly based on SPSS16.0 and Eviews 6.0.

\section{A. Data basic description}

The basic description of the sample data is shown in Table 1 below:

TABLE I. DATA BASIC DESCRIPTION

\begin{tabular}{|c|c|c|}
\hline & Number of people & Percentage \\
\hline Postgraduate & 36 & $16.36 \%$ \\
Employment & $93.27 \%$ & $42.73 \%$ \\
$1.36 \%$ \\
Non-Postgraduate and non-Employment & 94 & 3 \\
Postgraduate and Employment & & \\
\hline \multicolumn{2}{|c|}{ Note: Of the 36 students who succeed in postgraduate exam, 3 have found jobs at the same time; Of the 93 students who found jobs, 3 were admitted to be postgraduates. } \\
\hline
\end{tabular}

Table I shows that the college's Employment rate reached $42.27 \%$, nearly three times the Postgraduate rate. The total number of being postgraduate and getting employment reached nearly $60 \%$ of the total number of graduates of the Grade of 2011, and the number of those students without any result is less than half of the total number of students of this college. 
B. Analysis of the correlation between the attendance rate and the postgraduate rate and the employment rate

The results of the correlation analysis between the Attendance rate and the Postgraduate rate and the Employment rate are as follows. Table 2 shows that the correlation coefficient between the class rate and the postgraduate rate is -0.037 , the corresponding $p$ value is $0.583>0.05$, which has not passed the test, that is to say, there is no significant correlation between the attendance rate and the postgraduate rate. The correlation coefficient between attendance rate and employment rate is 0.009 , and the corresponding $\mathrm{p}$ value is $0.894>0$. 05 . It has not been tested, which shows that there is no significant correlation between attendance rate and employment rate. From the below table, we can also see that the correlation coefficient between the postgraduate rate and the employment rate is 0.279 . The corresponding $p$ value is $0.000<0.05$, which is significant enough to indicate that there is a significant negative correlation between the postgraduate rate and the employment rate. Of course, we do not need data analysis can also know that a person's time is limited, if the exam will inevitably delay looking for a job, the same job will also affect the effectiveness of the postgraduate entrance examination.

TABLE II. CORRELATION BETWEEN THE ATTENDANCE RATE AND THE POSTGRADUATE RATE AND THE EMPLOYMENT RATE

\begin{tabular}{|c|c|c|c|c|}
\hline & & $\begin{array}{l}\text { Attendance } \\
\text { Rate }\end{array}$ & $\begin{array}{l}\text { Postgraduate } \\
\text { Rate }\end{array}$ & Employment Rate \\
\hline \multirow[t]{5}{*}{ Attendance rate } & Pearson Correlation & 1 & -.037 & .009 \\
\hline & Sig. (2-tailed) & & .583 & .894 \\
\hline & $\begin{array}{l}\text { Sum of Squares and Cross- } \\
\text { products }\end{array}$ & 6.864 & -.536 & .174 \\
\hline & Covariance & .031 & -.002 & .001 \\
\hline & $\mathrm{N}$ & 220 & 220 & 220 \\
\hline \multirow[t]{5}{*}{ Postgraduate rate } & Pearson Correlation & -.037 & 1 & $-.279 * *$ \\
\hline & Sig. (2-tailed) & .583 & & .000 \\
\hline & $\begin{array}{l}\text { Sum of Squares and Cross- } \\
\text { products }\end{array}$ & -.536 & 30.109 & -11.218 \\
\hline & Covariance & -.002 & .137 & -.051 \\
\hline & $\mathrm{N}$ & 220 & 220 & 220 \\
\hline \multirow[t]{5}{*}{ Employment rate } & Pearson Correlation & .009 & $-.279 * *$ & 1 \\
\hline & Sig. (2-tailed) & .894 & .000 & \\
\hline & $\begin{array}{l}\text { Sum of Squares and Cross- } \\
\text { products }\end{array}$ & .174 & -11.218 & 53.686 \\
\hline & Covariance & .001 & -.051 & .245 \\
\hline & $\mathrm{N}$ & 220 & 220 & 220 \\
\hline
\end{tabular}

Through the above analysis we know that there is no inevitable relationship between the attendance rate and the postgraduate entrance rate and the employment rate. So students being absent to class will not assist their postgraduate examination, and their employment. Postgraduate exam or looking for jobs is just an excuse for not going to class.

\section{Granger causality test}

In order to further explore the causality relationship between the attendance rate of lessons, the postgraduate rate of entrance and the employment rate, we conducted a causality test, as shown in Table 3 and Table 4, where $\mathrm{z}$ represents the attendance rate, $\mathrm{x}$ represents the postgraduate rate, and y represents the employment rate. 
TABLE III. GRANGER CAUSALITY TEST BETWEEN ATTENDANCE RATE AND POSTGRADUATE ENTRANCE RATE

\begin{tabular}{|l|l|l|l|}
\hline Null Hypothesis: & Obs & F-Statistic & Prob. \\
\hline X does not Granger Cause Z & 218 & 4.41304 & 0.0132 \\
\hline Z does not Granger Cause X & 1.06403 & 0.3469 \\
\hline
\end{tabular}

TABLE IV. GRANGER CAUSALITY TEST BETWEEN ATTENDANCE RATE AND EMPLOYMENT RATE

\begin{tabular}{|l|l|l|l|}
\hline Null Hypothesis: & Obs & F-Statistic & Prob. \\
\hline Y does not Granger Cause Z & 218 & 0.48542 & 0.6161 \\
\hline Z does not Granger Cause Y & & 3.55398 & 0.0303 \\
\hline
\end{tabular}

\section{CONCLUSIONS}

The phenomenon of "empty nest" in Grade 4 students of universities causes the decline of quality of education and goal of education. As administrators of universities, we shall consider how to balance the relationship between standards of universities and the demands of students, how to formulate reasonable policies while not affecting the quality of teaching, and how can benefit the students' postgraduate exam and employment without weakening the teaching quality. Through the correlation analysis and causality analysis, based on the actual investigation data, it is found that there is no necessary relationship between the rate of attendance and the rate of postgraduate entrance examination and the employment rate. It is not necessary for the universities or related teachers to shrink the teaching for the purpose of increasing students' employment rate and postgraduate entrance rate, i.e. the goal of educating should be reduced. Instead, the idea of "opening sources" should be taken into account. I want to change the concept of management in student work, boldly reform the curriculum and increase the practical links, reform the teaching method, and strengthen the ideological education and employment education of students. As a result, the students are not willing to give up the last opportunity of education subjectively and take the initiative to return to classes.

\section{REFERENCES}

[1] Xiao Quanmin: A probe into the phenomenon of "Grade four" "Deficiency" in undergraduate Education and its Countermeasures [J].Educational Review, 2008(6), 31-32

[2] Dang Tingjun, Zhang Yuqin: The Cause Analysis and Countermeasures Research of the "Grade four phenomenon" in Local Universities [J] Modern Educational Science, 2009(3), 150-152

[3] Liu Xiaoxiong, Li Wenguang, Wu Yan: Several suggestions on how to improve University Grade four students' interest in Learning [J]. Innovation of Science and technology Education, 2008(2),243-246

[4] Li Qi, On the Education and Administration of University Grade four students [J]. Journal of Weinan Normal University, 2008(3),68-70

[5] Li Man, Tang Jingchao: Investigation and Analysis on the phenomenon of skipping classes among University Grade four students: a case study of the Light Industry School of Hebei University of Science and Technology [J]. China Electric Power Education, 2010(27), 170-172

[6] Zuo Yang: An Analysis of the solution to the problem of "Empty Nest in University Grade four" from the Perspective of university students' instructors [J].HeiLongJiang Education, 2011(5),44-45

[7] Du Xiaowu, Wu Xiaoou: An Analysis of the phenomenon of "Grader four" in university Education [J]. Administration Informatization of China, 2010(3),120-122

[8] Ding Sanqing: Reflection on the "Grader four" phenomenon in universities and its Countermeasures [J]. Coal Universities Education 2012(11), 4-6

[9] Yu Ze, Zhu Xuey: The reason Analysis and Countermeasure on the phenomenon of Grade four skipping Class [J]. China Electric Power Education, 2011(32), 177-178

[10] Gu Shuiliang: Systematic Analysis on the reasons and Solutions of College students skipping classes [J]. University Education, 2013(9), $148-150$

[11] Jiang Zhan: An Analysis of the phenomenon of empty nest in Grade four of Universities [J]. Journal of Sichuan Institute of Education 2012(4), 27-29

[12] Lin Yu: A probe into the phenomenon of Grade four students' absence from classes in Chinese Medicine Majors of traditional Chinese Medicine Universities [J]. Modern distance Education of Chinese traditional Medicine, 2013(1), 75-76

[13] Wang Zhibiao: The causes, effects and Countermeasures of College students skipping classes: an Analysis based on the investigation data of Henan Universities [J]. Journal of Inner Mongolia Normal University, 2012(9), 46-50

[14] Liu Jingyue: The Dilemma and Breakthrough of Teaching Management in the fourth year of Researching Type University: An empirical study based on Nanjing University [J]. College education management, 2012(3), 99-103

[15] Zhao Xianzhou: On the Teaching Management Reform in Universities from the Perspective of University students skipping classes: An empirical study based on the Survey data of a University [J]. Education and Teaching Research, 2011(12), 69-80

[16] Dang Peiying, Zhang Binpeng, Yang Fang: A Statistical Analysis on the Construction of Learning Ethos in Independent College from to the Class Attendance rate: taking the School of Northern Information Engineering of Xi'an University of Industry as an example [J]. Science and Education Guide Journal: 2013(1), 14 -16

[17] Lou Runping, Sheng Ge, Yang Defeng: An empirical study on the effect of College students skipping classes on examination results [J]. Examination study 2012(4), 44-50

[18] Ruan Guihai: Data Statistics and Analysis-SPSS Application course [M] Press of Peking University, 2005(1), 232.

[19] Gao Tiemei: Methods and models of econometric analysis [M]. Press of Tsinghua University, 2009(5), 465. 